\title{
Redução dos custos na geração de ar comprimido em instalações industriais
}

Jaisson Vidal

pressure.engenharia@gmail.com

Universidade Federal de Santa Catarina

(UFSC), Joinville, Santa Catarina, Brasil
O ar comprimido é tão útil quanto a eletricidade em diversas aplicações dentro das plantas industriais, sendo raros os processos de produção que não se utilizem deste poderoso fluido. A amplitude da utilização de sistemas de ar comprimido traz consigo uma série de desperdícios de energia, acompanhada da falta de conscientização das inúmeras oportunidades existentes de melhorias de eficiência das instalações responsáveis pela compressão do ar. Uma grande fatia da fatura de energia elétrica das indústrias corresponde à geração de ar comprimido, que, se desperdiçado, se traduz em dinheiro desperdiçado. O objeto deste artigo é demonstrar procedimentos para uma melhor eficiência na produção e utilização do ar comprimido, podendo assim quantificar a economia de dinheiro associada a cada técnica. Dentre os tópicos abordados estão: os vazamentos de ar, a temperatura de admissão do ar pelo compressor, a pressão máxima de trabalho da linha, e o consumo de ar em filtros de manga do tipo pulse-jet. Os resultados de cada procedimento comprovam que técnicas de gerenciamento de custos, e até mesmo um maior controle e acompanhamento do consumo e produção do ar comprimido, trazem retornos econômicos satisfatórios.

PALAVRAS-CHAVE: Ar comprimido. Eficiência. Economia. 


\section{INTRODUÇÃO}

Os compressores de ar são equipamentos largamente utilizados nas plantas industriais, com a finalidade de comprimir o ar e usá-lo nas mais diversas atividades, seja para movimentar um cilindro pneumático em uma máquina, seja para a realização de limpezas, ou para o acionamento de uma bomba de diafragma, sem o ar comprimido muitos processos produtivos não poderiam ser realizados. Aliado à valiosa contribuição que o ar comprimido fornece às indústrias, vem o custo necessário para a compressão do mesmo, sendo considerado um dos processos mais caros dentro da indústria.

Como o custo de operação e geração do ar comprimido é um dos mais elevados, a energia utilizada para a compressão é ligada a isso. Estima-se que os custos operacionais com os compressores de ar oscilam em torno de $70 \%$ do total da fatura de energia elétrica anual das empresas. Diante desse cenário é de extrema importância que os gerenciamentos de energia elétrica nas empresas integrem os sistemas de ar comprimido em seus programas de eficiência energética (RISI, 1995).

Há diferentes aplicações de uso final do ar comprimido nas empresas, e o campo de aplicação cresce a cada dia, com isso o conhecimento do balanço energético característico do sistema é imprescindível, identificando assim muitas das perdas que contribuem de forma expressiva para a redução da eficiência energética, conforme mostra a Figura 01, desta forma, conhecendo o sistema é possível identificar diversas oportunidades para a maximização da eficiência, e consequentemente, redução de custos (ROCHA, MONTEIRO, 2005).

Figura 01: Perdas características em sistemas de ar comprimido.

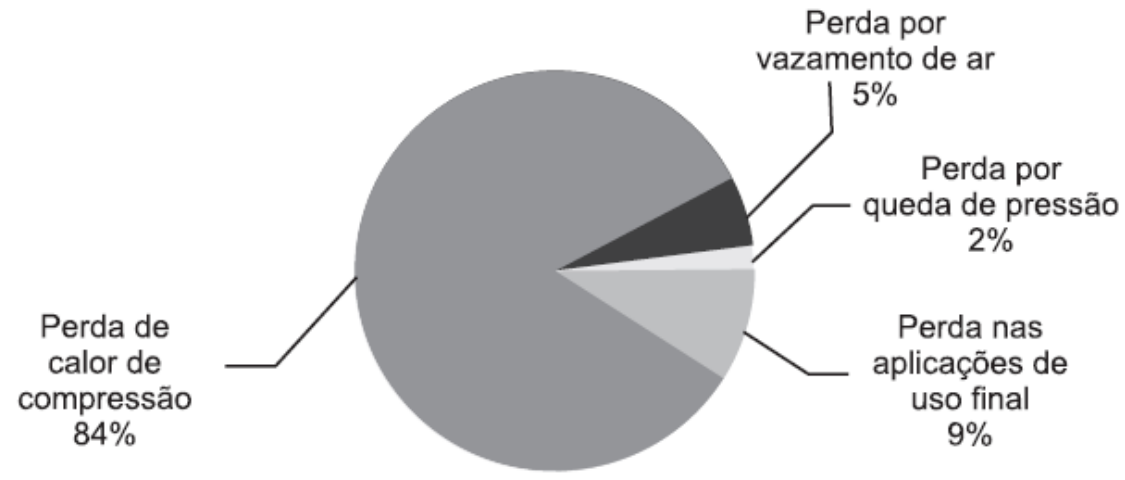

Fonte: Rocha e monteiro (2005).

Redução de custos nas empresas é um tema muito abordado diante da crise vivida no país. Inúmeras publicações envolvem e relacionam custos todos os anos, e precisa ser cada vez mais explorado, para desta forma difundir assuntos muitas vezes desconhecidos pelos gestores, facilitando assim em tomadas de decisões e investimentos necessários para melhorias nos processos, inclusive em investimentos de maximização da eficiência energética em sistemas de ar comprimido.

Diante do cenário exposto, o objetivo deste trabalho é identificar oportunidades de conservação de energia em sistemas de ar comprimido, que 
são relativamente fáceis na aplicação, porém com resultados econômicos relevantes. Simulações matemáticas são feitas para demonstrar diversos cenários de consumo de energia nestes sistemas.

\section{REFERENCIAL TEÓRICO}

O presente referencial bibliográfico traz a compreensão de sistemas de ar comprimido eficientes, dos sistemas de limpeza dos filtros de manga do tipo pulse-jet, bem como a termodinâmica por trás da compressão do ar, onde fatores como pressão e temperatura são essenciais para uma boa eficiência.

\section{OPERAÇÃO EFICIENTE DOS COMPRESSORES DE AR}

Os compressores de ar são dispositivos que fornecem energia para aumentar a pressão do ar atmosférico, e posteriormente armazená-lo em um recipiente denominado vaso de pressão, para que então possa ser utilizado nas atividades produtivas. Os sistemas de ar comprimido, de forma geral, são divididos em três principais subsistemas, sendo (TALBOTT, 1993):

a) Compressores: onde se inclui o motor de acionamento, partes elétricas como inversores e drives, filtro de ar, recuperadores de calor, etc.;

b) Equipamentos para condicionamento do ar: separadores, purgadores, secadores, etc.;

c) Equipamentos de distribuição: tubulações, filtros adicionais, conectores, válvulas, reguladores de pressão, etc.

A escolha e a modelagem da rede de ar comprimido nas indústrias são fatores fundamentais para uma boa eficiência. Identificar a localização dos principais pontos de consumo de ar comprimido, e desta forma definir o melhor local para a instalação da casa de compressores. Também é necessário calcular todas as tubulações de forma que se tenha a pressão desejada em todos os pontos de consumo, tornando o sistema eficiente (HORTA, 2004).

Um dos principais requisitos em um sistema de ar comprimido é que a pressão seja constante em toda a linha, e que se tenha a vazão necessária requerida em cada equipamento da planta. Levando em conta o grande consumo de energia para a produção de ar comprimido, a escolha de dispositivos que controlem o sistema de forma segura e eficiente é imprescindível. A forma mais comum deste controle é reduzir a rotação do motor do compressor a medida que pressão da linha chega em seu ponto máximo, ou ainda fazendo o compressor trabalhar no vazio, gastando assim menos energia (EDWARDS, 1988).

\section{FATORES TERMODINÂMICOS NA EFICIÊNCIA}

O fator preponderante e quantitativo na compressão se trata do trabalho (w) realizado para comprimir certa quantidade de gás, que em um processo reversível está intimamente ligado aos estados iniciais e finais do fluido. Desta forma, o trabalho realizado (para fora do sistema), expresso em $\mathrm{kJ} / \mathrm{kg}$, de acordo com a primeira lei da termodinâmica, em um dispositivo operando em regime permanente, pode ser escrito na forma diferencial, conforme mostra a expressão (01) abaixo (SONTAG, 2013): 


$$
\delta q_{r e v}-\delta w_{r e v}=d h+d e c+d e p
$$

Integrando a expressão acima, e considerando que as variações de energia cinética e potencial são nulas, o que se torna muito plausível para compressores, pode-se reescrever a equação na forma (02), em kJ/kg (ÇENGEL,BOLES 2006):

$$
w_{r e v}=\int_{1}^{2} v d P
$$

A expressão acima é de suma importância para a engenharia, principalmente no que tange à dispositivos que operam em regime permanente e produzem trabalho, pois a mesma deixa evidente a forte dependência do volume específico $(v)$ sobre o trabalho realizado, ou seja, quanto maior for o volume específico do gás que escoa pelo dispositivo, maior será o trabalho reversível produzido ou consumido pelo equipamento, e quanto menor o volume específico, menor o trabalho realizado (MORAN, SHAPIRO, 2013).

Para que o compressor possa ter o mínimo de trabalho é necessário que a temperatura de admissão seja a menor possível, uma vez que a temperatura é diretamente proporcional ao volume específico, assim, menor será o trabalho realizado para comprimir esse gás, essa é uma das formas eficientes para minimizar de forma expressiva o trabalho realizado pelo sistema de compressão (FELLER, 1944).

Segundo Çengel e Boles (2006) uma comparação entre três tipos de processos de compressão, sendo: um processo isoentrópico (03) (não há resfriamento do ar), um processo politrópico (04) (há um resfriamento médio), e um processo isotérmico (05) (há resfriamento máximo do ar), obtém-se um melhor entendimento do trabalho realizado durante estes processos. Levando em conta que os três processos sejam executados nas mesmas faixas de pressões $\left(P_{1} e P_{2}\right)$, e que o fluido se comporte como gás ideal $(P v=R T)$ :

$$
\begin{aligned}
& w_{\text {comp }}=\frac{k R\left(T_{2}-T_{1}\right)}{k-1}=\frac{k R T_{1}}{k-1}\left[\left(\frac{P_{2}}{P_{1}}\right)^{\left(\frac{k-1}{k}\right)}-1\right] \\
& w_{\text {comp }}=\frac{n R\left(T_{2}-T_{1}\right)}{n-1}=\frac{n R T_{1}}{n-1}\left[\left(\frac{P_{2}}{P_{1}}\right)^{\left(\frac{n-1}{n}\right)}-1\right] \\
& w_{\text {comp }}=\operatorname{RT} \ln \frac{P_{2}}{P_{1}}
\end{aligned}
$$

Onde $\mathrm{n}$ e $\mathrm{k}$ são as razões dos calores específicos do ar, e $\mathrm{R}$ a constante do ar, em (kJ/kg.K). Dos casos expostos acima é interessante ressaltar que o processo de compressão adiabática (03) exige o máximo de trabalho, enquanto a compressão descrita pelo processo (05), isotérmico, exige o mínimo de trabalho na compressão, e o processo politrópico (04) fica entre os dois processos.

Segundo Bejan (1997), a redução do trabalho realizado pelo compressor quando se diminui a temperatura de admissão é evidente quando se analisam as expressões matemáticas, e procedimentos simples podem ser tomados para uma 
redução substancial da temperatura de entrada do ar de admissão no sistema de compressão.

Para Çengel, Cerci (2000) o maior trabalho realizado por um compressor é para suprir a queda na pressão da linha, ocorrida devido aos vazamentos de ar. Segundo os estudos realizados, as plantas industriais perdem cerca de $40 \%$ do ar comprimido em vazamentos, porém a eliminação de todos os vazamentos tornase uma tarefa quase impossível, mas de acordo com o estudo uma taxa de $10 \%$ de vazamentos ainda é considerada aceitável. Esses vazamentos têm origem em buchas, conexões, mangueiras ressecadas, cotovelos, filtros, entre outros acessórios. Assim, uma boa prática é sempre verificar todos esses detalhes e evitar os vazamentos.

Os vazamentos de ar podem ser ouvidos, muitas vezes, mesmo em instalações industriais com alto nível de ruído. Esses vazamentos são quantificados pela energia mecânica desperdiçada, que equivale à mesma energia que será necessária para repor esse ar comprimido que vazou. Pode ser expresso pela equação (06), com unidade kJ/kg, (ÇENGEL; BOLES, 2006):

$$
w_{\text {comp }}=\frac{w_{\text {comp }, \text { rev }}}{\eta_{\text {comp }}}=\frac{n R T_{1}}{\eta_{\text {comp }}(n-1)}\left[\left(\frac{P_{2}}{P_{1}}\right)^{\left(\frac{n-1}{n}\right)}-1\right]
$$

Onde $\mathrm{n}=1,4$, para uma compressão isoentrópica de ar, e $\eta_{\text {comp }}$ a eficiência do compressor, que gira em torno de 0,75 a 0,95, dependendo do modelo e ano do equipamento.

Os pontos de vazamento existentes são geralmente quantificados pela área do orifício por onde essa massa de ar escapa. Esse fluxo de massa de ar em kg/s que percorre pelo furo do vazamento pode ser expresso por (07), usando a teoria de escoamento compressível (FOX; MCDONALD, 2010):

$$
m_{a r}=\left(\frac{2}{k+1}\right)^{\frac{1}{k-1}}\left[k R\left(\frac{2}{k+1}\right) T_{t u b}\right]^{\frac{1}{2}} \frac{P_{t u b}}{R T_{t u b}} \cdot A \cdot C_{d e s c}
$$

Onde é a razão dos calores específicos, e pode ser assumido $k=1,4$ para $o$ ar, e $C_{\text {desc }}$ o coeficiente de descarga, para escoamentos de vazamentos de ar pode ser aproximado em 0,65 , uma vez que geralmente são orifícios de geometria indefinida.

Para Dindorf, (2010), os compressores geralmente são instalados no interior das plantas industriais, onde o ar captado geralmente está numa temperatura maior que a temperatura ambiente, devido à dissipação de calor pelo motor do compressor e pelo trabalho de compressão. Como o ar fora do prédio está a uma temperatura menor, aconselha-se a instalação de um duto de admissão no compressor para que o ar seja admitido do lado externo do prédio com uma temperatura reduzida (em Kelvin). Se a temperatura reduzir em $4 \%$, a potência será reduzida em $4 \%$ no compressor. Esse fator de redução de potência provém da 1 으 Lei da Termodinâmica, e pode ser expressa por (08), resultando num percentual:

$$
f_{\text {red }}=\frac{w_{\text {comp,int }}-w_{\text {comp }, \text { ext }}}{w_{\text {comp }, \text { int }}}=1-\frac{T_{\text {exterior }}}{T_{\text {interior }}} \times 100
$$


Para Monteiro e Rocha (2005), outra fonte de desperdício presente nos complexos industriais é a linha de ar comprimido trabalhando com a pressão máxima acima da requerida pelo parque produtivo, desta forma o compressor gastará mais energia para comprimir o ar até uma pressão a qual nem será utilizada, muitas vezes somente para atender à um equipamento específico que se tenha picos elevados de vazão, e consequentemente requer que a pressão da linha compense essa queda. Porém esse problema pode ser facilmente resolvido instalando um reservatório de ar ao lado da máquina, desta forma em picos de consumo a máquina em questão vai utilizar do ar proveniente do reservatório, sem oscilar a pressão da rede mestre, evitando assim que diminua a pressão em outros equipamentos. O cálculo deste fator de redução, deriva da 1 으 Lei da Termodinâmica, e pode ser expresso por (09), resultando em um percentual de redução:

$$
f_{\text {red }}=\frac{w_{\text {comp,atual }}-w_{\text {comp }, \text { reduzido }}}{w_{\text {comp,atual }}}=1-\frac{\left(\frac{P_{2, \text { reduzido }}}{P_{1}}\right)^{\frac{n-1}{n}}-1}{\left(\frac{P_{2}}{P_{1}}\right)^{\frac{n-1}{n}}-1} \times 100
$$

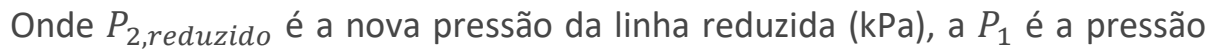
atmosférica do ar $(\mathrm{kPa})$, e $P_{2}$ a pressão máxima da linha antes da redução. Tanto a expressão (08) quanto a expressão (09) mostram maneiras de redução de potência, relacionadas à temperatura e pressão, respectivamente.

Após ter os valores mensurados das expressões (06), (07), (08) e (09) podese calcular a potência economizada com as reduções de pressão e temperatura, economia de energia, e consequentemente a economia de dinheiro, conforme mostram as equações (10), (11) e (12), respectivamente (ÇENGEL e BOLES, 2006):

$$
\text { Potência econ. }=m_{\text {ar }} w_{\text {comp }}[\mathrm{kW}]
$$

$$
\text { Econ. de energia }=\frac{(\text { Potência econ. } x \text { horas de operação })}{\eta_{\text {motor }}}\left[\frac{k W h}{\text { ano }}\right]
$$

Econ. dinheiro $=$ Econ. de energia $x$ Custo unit.da energia $[R \$ /$ ano $]$

\section{SISTEMA DE LIMPEZA DAS MANGAS DOS FILTROS PULSE-JET}

Os coletores do tipo filtro de mangas são muito utilizados nas indústrias no ramo de ventilação de exaustão local, este método de remoção de partículas caracteriza-se pela passagem forçada do ar contaminado por meio de tecidos fibrosos, sendo este denominado por "mangas", devido sua forma construtiva lembrarem uma manga do nosso vestuário cotidiano, sendo que este tipo de tecido de filtragem é variado de acordo com a aplicação, porém o uso de mangas de poliéster agulhado é muito comum devido a sua gama de aplicações e pela sua alta eficiência de filtragem, porém essas mangas necessitam de uma limpeza em intervalos de tempos pré-programados, com objetivo de soltar os resíduos que impregnaram na manga devido à filtragem. $\mathrm{O}$ sistema de limpeza é chamado de 
pulse-jet, devido aos pulsos de ar comprimido que as mangas recebem a cada instante de forma programada e automática (MACINTYRE, 1990).

As indústrias moveleiras e madeireiras utilizam os filtros de ar do tipo pulsejet em larga escala, isso se dá ao fato de que quase todos os seus processos produzem uma quantia muito grande de resíduos, devido às atividades produtivas como usinagem, cortes com serras, lixação, entre outros. O sistema de limpeza é feito com ar comprimido da rede, porém neste sistema utiliza-se de válvulas de alta vazão, as quais conectam tubos na sua saída até cada manga, onde cada válvula realiza um jato de ar comprimido para a limpeza de uma fileira de mangas que varia de acordo com o tamanho do filtro, conforme mostra a Figura 02 abaixo (ACGIH: INDUSTRIAL VENTILATION MANUAL, 1998).

Figura 02: Filtro de mangas do tipo pulse-jet.

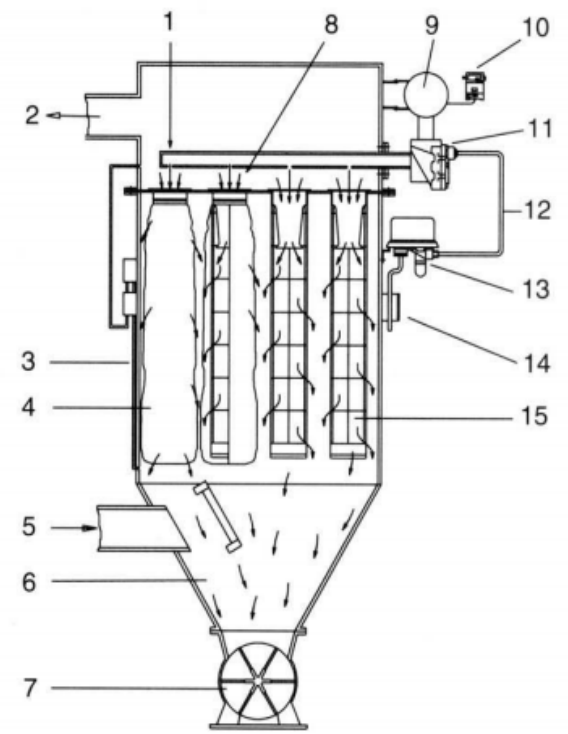

1.Jato de ar comprimido

2.Exaustor de ar limpo

3.Carcaça do Filtro

4.Manga do Filtro

5.Entrada de ar sujo

6.Área para deposição do coletor de pó

7.Válvula rotativa

8.Ar secundário

9.Ar de alimentação

10.Pressostato

11.Válvula do coletor de pó

12.Tubulação de controle de ar (auxiliar)

13.Bloco de válvulas

14.Controlador seqüencial

15. Gaiola manga (exibida sem a manga)

Fonte: ACGIH: Industrial Ventilation Manual (1998).

O jato de ar proveniente da abertura da válvula de alta vazão provocará uma onda de choque que percorrerá o tecido da manga no sentido inverso ao fluxo de exaustão, fazendo com que os particulados sólidos retidos pelo tecido da manga caiam para a área de deposição de pó, conforme ilustra a figura 02 acima. A duração do jato de ar varia de acordo com a finalidade da instalação, com o material do particulado, e com o intervalo entre um jato e outro, oscilando entre 100 e 500 milissegundos, e o intervalo entre um pulso e outro na ordem de 3 a 6 minutos. Cada pulso de ar descarregado pela válvula de alta vazão faz a limpeza de uma fileira de mangas (ASCOVAL, 2010).

\section{METODOLOGIA}

A presente pesquisa traz consigo uma abordagem quantitativa, que de acordo com Fonseca (2002), recorre à linguagem matemática para uma descrição detalhada dos fenômenos que ocorrem, as condições de trabalho, entre outras variáveis que estão relacionadas, interferindo no resultado final. Tendo como base o pensamento lógico positivista, priorizando as regras da lógica e fatores que são mensuráveis da experiência humana. 
Quanto à natureza, trata-se de pesquisa aplicada onde tem-se como um dos principais objetivos gerar conhecimentos que resultem em aplicação prática, focando em problemas específicos de interesses locais, neste caso, de interesse principalmente, industrial.

A pesquisa, no que tange aos objetivos, pode ser classificada como pesquisa exploratória e descritiva. Segundo Gil (2007), a pesquisa exploratória objetiva proporcionar uma maior familiaridade com os problemas descritos, com a finalidade de torna-los mais explícitos, que envolvem o levantamento bibliográfico, experiências já vivenciadas com o problema analisado, e uma análise detalhada de exemplos que tenham a finalidade de estimular uma melhor compreensão.

Já a pesquisa descritiva, para Seabra (2001), exige que o pesquisador tenha um profundo conhecimento das informações do problema que deseja estudar, sendo que este tipo de pesquisa pretende descrever todos os fatos envolvidos de um determinado problema real.

Quanto aos procedimentos de pesquisa foram utilizados: pesquisa bibliográfica, pesquisa em artigos técnicos e científicos, dados de fabricantes, manuais técnicos, livros clássicos, e simulação numérica em Python para geração de gráficos e resultados, com base nas expressões matemáticas e dados de artigos analisados.

\section{IDENTIFICANDO AS SITUAÇÕES ESTUDADAS}

Foram analisadas diversas situações relacionadas ao consumo de ar comprimido dentro das indústrias, mostrando os impactos financeiros que estas situações geram.

\section{Vazamentos de ar comprimido}

A simulação 01 trata-se da análise detalhada sobre os impactos dos vazamentos de ar comprimido numa instalação industrial. Onde foi realizado diversos cenários, envolvendo a pressão da linha $\left(P_{l}[\right.$ bar $\left.]\right)$, a pressão atmosférica $\left(P_{a}[\right.$ bar $\left.]\right)$, a temperatura de admissão do ar pelo compressor $\left(T_{a}\left[{ }^{\circ} \mathrm{C}\right]\right)$, a temperatura da linha $\left(T_{l}\left[{ }^{\circ} \mathrm{C}\right]\right)$, as horas trabalhadas pelo compressor no ano (H. $\operatorname{Tr}[\mathrm{h}])$, a eficiência do compressor $\left(\eta_{\text {comp }}\right)$ e do motor $\left(\eta_{\text {motor }}\right)$, e por fim os diâmetros do furo em milímetro $\left(\emptyset_{\text {furo }}\right)$, sendo este último o grande causador do desperdício de energia. O Quadro 01 abaixo mostra os dados da simulação.

Quadro 01: Variáveis estudadas na simulação 01.

\begin{tabular}{|c|c|c|c|c|c|c|c|}
\hline$P_{l}[\mathrm{bar}]$ & $P_{a}[\mathrm{bar}]$ & $T_{a}\left[{ }^{\circ} \mathrm{C}\right]$ & $T_{l}\left[{ }^{\circ} \mathrm{C}\right]$ & $H . \operatorname{Tr}[\mathrm{h}]$ & $\eta_{\text {comp }}$ & $\eta_{\text {motor }}$ & $\emptyset_{\text {furo }}$ \\
\hline $\mathbf{9 , 0}$ & 1,01 & 25,0 & 26,0 & 4500 & 0,80 & 0,99 & 1 a 10 \\
\hline $\mathbf{8 , 5}$ & 1,01 & 25,0 & 26,0 & 4500 & 0,80 & 0,99 & 1 a 10 \\
\hline $\mathbf{8 , 0}$ & 1,01 & 25,0 & 26,0 & 4500 & 0,80 & 0,99 & 1 a 10 \\
\hline $\mathbf{7 , 5}$ & 1,01 & 25,0 & 26,0 & 4500 & 0,80 & 0,99 & 1 a 10 \\
\hline $\mathbf{7 , 0}$ & 1,01 & 25,0 & 26,0 & 4500 & 0,80 & 0,99 & 1 a 10 \\
\hline $\mathbf{6 , 5}$ & 1,01 & 25,0 & 26,0 & 4500 & 0,80 & 0,99 & 1 a 10 \\
\hline $\mathbf{6 , 0}$ & 1,01 & 25,0 & 26,0 & 4500 & 0,80 & 0,99 & 1 a 10 \\
\hline
\end{tabular}

Fonte: Autoria própria (2019). 
Os dados apresentados no quadro acima mostram sete simulações, que se diferenciam pelas pressões, ou seja, o impacto financeiro causado pelos furos dos vazamentos tem valores diferentes dependendo da pressão de trabalho da linha, considerando o ar como gás ideal, e considerando ainda as características do compressor descritas no quadro. Desta forma obtendo como resultados desta simulação os custos provenientes dos vazamentos, variando com o diâmetro do vazamento e pressão de trabalho da linha de ar comprimido.

\section{Temperatura de admissão do ar}

Os compressores por se encontrarem, na maioria das vezes, em ambientes internos das empresas, submetidos ao calor não operam na sua máxima eficiência, devido ao ar de admissão da compressão estar em uma temperatura muito elevada, sendo aconselhada a instalação de dutos de admissão, com a finalidade de aspirar o ar exterior para a compressão.

Sendo assim, a simulação 02, busca expressar a economia de energia, e consequentemente, de dinheiro, uma vez que o ar é admitido a uma temperatura bem menor quando comparada ao ar do interior da empresa, ou no interior da sala onde se encontra o sistema de compressão de ar, ou seja, a temperatura interna do ar no quadro refere-se à temperatura de admissão do compressor antes da redução, já a temperatura externa retrata a temperatura nova de admissão, resultando num percentual de redução conforme mostra o Quadro 02:

Quadro 02: Dados de simulação de economia reduzindo a temperatura do ar de admissão.

\begin{tabular}{|c|c|c|}
\hline $\begin{array}{c}\text { Temperatura interna do } \\
\text { ar }\left[{ }^{\circ} \mathrm{C}\right]\end{array}$ & $\begin{array}{c}\text { Temperatura do ar } \\
\text { externa (admissão) }\left[{ }^{\circ} \mathrm{C}\right]\end{array}$ & $\begin{array}{c}\text { Percentual de Redução } \\
{[\%]}\end{array}$ \\
\hline 45 & 42 & $1 \%$ \\
\hline 45 & 40 & $1,6 \%$ \\
\hline 45 & 35 & $3,1 \%$ \\
\hline 45 & 30 & $4,7 \%$ \\
\hline 45 & 25 & $6,3 \%$ \\
\hline 45 & 20 & $7,9 \%$ \\
\hline
\end{tabular}

Fonte: Autoria própria (2019).

Os dados acima representam os percentuais relacionados à redução de temperatura na admissão do ar para compressão. Em média a cada $3^{\circ} \mathrm{C}$ de redução representa uma minimização de $1 \%$, sendo que este fator percentual impactará drasticamente nos resultados, gerando elevadas economias.

\section{Pressão máxima da linha de ar}

Em muitas plantas industriais encontram-se sistemas de ar comprimido trabalhando acima de sua pressão máxima necessária para a linha, isso se dá ao fato de favorecer determinado ponto de consumo, pois algumas máquinas têm picos elevados de vazão de ar em determinados momentos, fazendo com que a pressão da linha reduza assim algumas plantas optam por trabalhar muito acima da pressão nominal necessária, para que não prejudique outros processos. 
A melhor alternativa para a resolução desta queda de pressão é a instalação de reservatórios de ar comprimido ao lado das máquinas que possuem altos picos de vazão, podendo assim reduzir a pressão máxima de trabalho do compressor, economizando assim energia. Abaixo, no Quadro 03, são mostrados os dados da simulação 03, em faixas de reduções de pressão, ou seja, a pressão antes da redução, a pressão após a redução, e o percentual de redução obtido nesta mudança:

Quadro 03: Dados para simulação de economia na redução de pressão.

\begin{tabular}{|c|c|c|}
\hline Pressão de linha [bar] & $\begin{array}{c}\text { Pressão de linha } \\
\text { reduzida [bar] }\end{array}$ & $\begin{array}{c}\text { Percentual de Redução } \\
{[\%]}\end{array}$ \\
\hline 7,5 & 7,0 & $4,5 \%$ \\
\hline 7,5 & 6,5 & $9,2 \%$ \\
\hline 7,5 & 6,0 & $14,2 \%$ \\
\hline 7,5 & 5,5 & $19,4 \%$ \\
\hline 7,5 & 5,0 & $25,0 \%$ \\
\hline
\end{tabular}

Fonte: Autoria própria (2019).

Acima vemos alguns dados de redução do valor máximo de pressão da linha de ar comprimido, esse ajuste da pressão leva a grandes economias de potência e que se nota nos resultados apresentados a frente. Em média uma redução de meio bar na pressão, considerando a pressão atmosférica de 1,01 bar, pode-se perceber que a redução alcança os incríveis $4,5 \%$, onde refletirá na economia e redução de custos.

\section{Redução no tempo de limpeza das mangas nos filtros do tipo pulse-jet}

Como visto anteriormente, um dos grandes consumidores de ar comprimido são os sistemas de limpeza dos filtros pulse-jet, que por meio de poderosos jatos de ar limpam os resíduos impregnados nas mangas. Como esses jatos são monitorados e controlados por tempo de abertura da válvula, a simulação 04 busca explicitar o consumo em diferentes pulsos do ar de limpeza.

Há muitas ocasiões da redução do tempo de limpeza, em muitas situações os tempos são demasiados, e reduções na ordem de alguns milissegundos impactam de forma expressiva na economia ao longo do ano, conforme mostrado nos resultados. A simulação 04 se baseou nos dados descritos no Quadro 04 abaixo:

Quadro 04: Dados para simulação de economia na redução do tempo de limpeza em filtros.

\begin{tabular}{|c|c|c|}
\hline Pressão de linha [bar] & $\begin{array}{c}\text { Intervalo dos jatos } \\
\text { entre as fileiras de } \\
\text { mangas [s] }\end{array}$ & $\begin{array}{c}\text { Faixa para redução do } \\
\text { tempo do jato de limpeza } \\
{[\mathrm{ms}]}\end{array}$ \\
\hline 6,5 & 10 & 500 até 50 \\
\hline 6,5 & 15 & 500 até 50 \\
\hline 6,5 & 20 & 500 até 50 \\
\hline 6,5 & 25 & 500 até 50 \\
\hline 6,5 & 30 & 500 até 50 \\
\hline
\end{tabular}

Fonte: Autoria própria (2019). 
Os intervalos de pulsos e duração dos pulsos dependem do material do resíduo e da demanda de produção do momento. Cabe ao departamento de gestão da manutenção avaliar cada situação, reduzindo ao máximo os tempos de limpeza sem que haja saturação das mangas, ganhando assim em economia de energia e economia de dinheiro, como se apresenta os resultados obtidos pelas simulações.

\section{RESULTADOS E DISCUSSÕES}

Os resultados obtidos trazem o grande consumo de energia associado a cada simulação, e consequentemente o desperdício de dinheiro ou economia de dinheiro, dependendo da ação. Verifica-se que os vazamentos de ar nas empresas são muito indesejáveis e causam prejuízos altos quando não reparados, e em muitos casos até ignorados.

Nota-se também uma grande economia quando se diminui a temperatura do ar de admissão, sendo este um procedimento simples e com um retorno financeiro muito satisfatório, como também acontece com a redução de pressão da linha, e com a redução dos tempos de limpeza das mangas dos filtros do tipo pulse-jet.

\section{CUSTOS RELACIONADOS AOS VAZAMENTOS}

Os resultados obtidos com os dados do Quadro 01 mostram a grande influência dos vazamentos sobre a fatura de energia elétrica, uma vez que quanto maior o diâmetro por onde ocorre o vazamento maior será a potência necessária para suprir esse vazamento, fazendo com que o compressor de ar realize mais trabalho, pois o mesmo trabalho que o sistema realiza para comprimir uma massa de ar será realizado novamente.

A Figura 03 abaixo mostra com clareza essa relação, onde foi simulado diversos diâmetros de vazamentos (0 a $10 \mathrm{~mm}$ ), para um sistema de ar comprimido com as seguintes características:

- Eficiência do compressor: 0,80;

- Pressões de linha: 6,0 a 9,0 bar (conforme gráfico da Figura 03);

- Pressão atmosférica: 1,01 bar (a nível do mar);

- Razão entre os calores específicos do ar: 1,4;

- Temperatura do ar na linha: $26^{\circ} \mathrm{C}(299 \mathrm{~K})$;

- Temperatura do ar de admissão: $25^{\circ} \mathrm{C}(298 \mathrm{~K})$;

- Regime de trabalho do compressor: 4200 horas/ano

- Eficiência do motor do compressor: 0,99;

- Custo unitário de energia: $\mathrm{R} \$ 0,355$ / kWh;

- Constante do gás (AR): 0,2870 kJ/kg.K;

- Coeficiente de descarga: 0,65.

Vale ressaltar que o valor de potência gasta com os vazamentos pode ser maior que a informada na Figura 03 a seguir, dependendo do regime de trabalho do compressor durante o ano, também da temperatura média de admissão do ar, que quanto mais elevada maior será o trabalho do compressor para realizar a compressão.

Com isso os resultados obtidos reforçam a importância de manter um plano de manutenção para eliminar os possíveis vazamentos de ar nas plantas 
industriais, pois com procedimentos muito simples e de baixa custo podem trazer economias de dinheiro bem satisfatórias no final do ano.

Figura 03: Relação da potência necessária para suprir os vazamentos até $10 \mathrm{~mm}$.

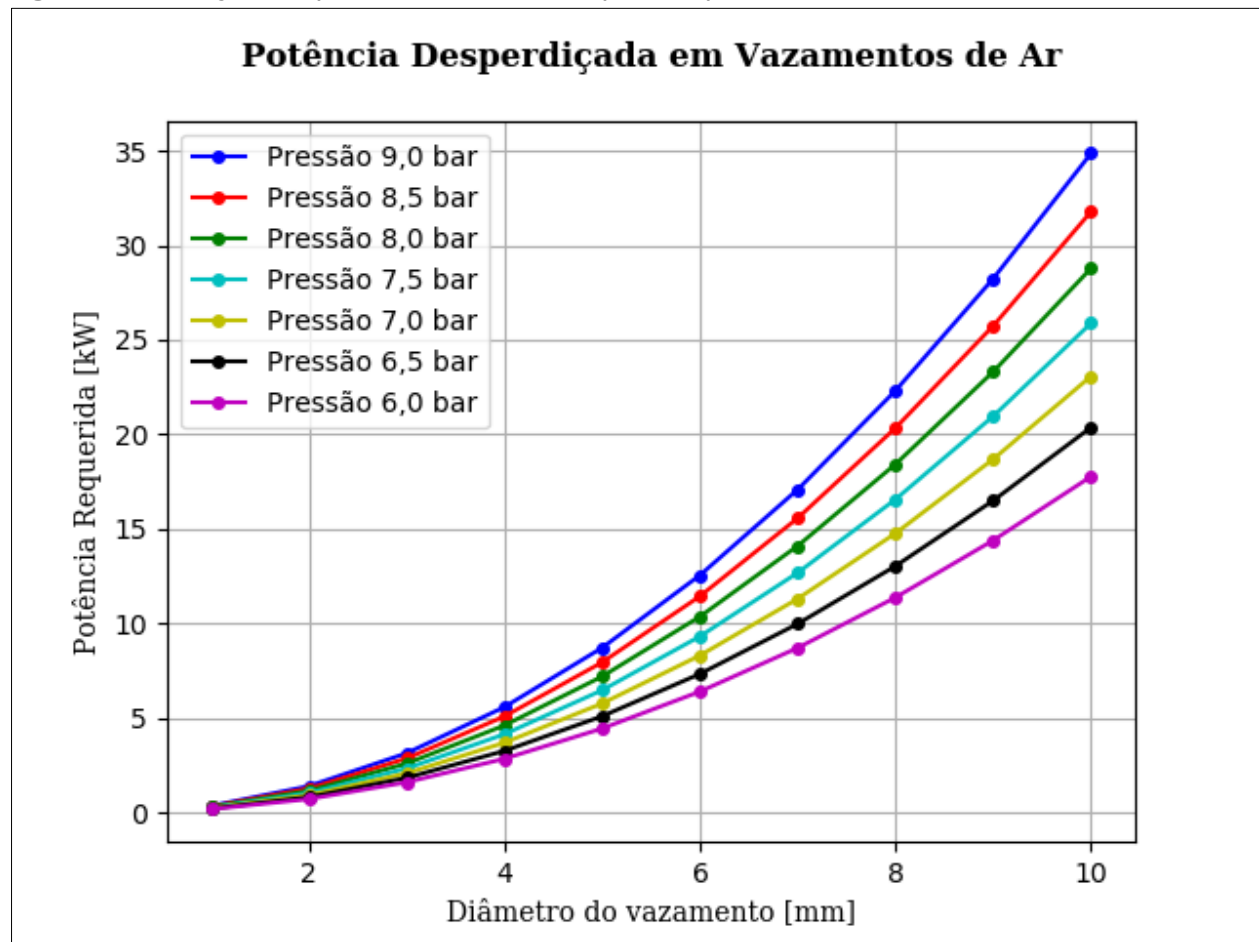

Fonte: Autoria própria (2019).

O Quadro 05 abaixo mostra o detalhamento dos valores gastos com o desperdício de energia para suprir os vazamentos de ar do caso acima, sendo que esses valores podem ser interpretados como desperdício ou como economia, no caso de vazamentos com o diâmetro relacionado que foram consertados.

Quadro 05: Despesas anuais com vazamentos de acordo com a pressão de trabalho.

\begin{tabular}{|c|c|c|c|c|c|}
\hline \multicolumn{6}{|c|}{ Custo Anual Relacionado aos Vazamentos de Ar Comprimido } \\
\hline $\begin{array}{l}\text { Pressão } \\
\text { da linha }\end{array}$ & $\begin{array}{c}\text { Furo } \\
\emptyset 2 \mathrm{~mm}\end{array}$ & $\begin{array}{c}\text { Furo } \\
\varnothing 4 \mathrm{~mm}\end{array}$ & $\begin{array}{c}\text { Furo } \\
\varnothing 6 \mathrm{~mm}\end{array}$ & $\begin{array}{c}\text { Furo } \\
\varnothing 8 \mathrm{~mm}\end{array}$ & $\begin{array}{c}\text { Furo } \\
\varnothing 10 \mathrm{~mm}\end{array}$ \\
\hline 6,0 bar & $\mathrm{R} \$ 1.070,72$ & $\mathrm{R} \$ 4.282,89$ & $\mathrm{R} \$ 9.636,50$ & $\begin{array}{l}\mathrm{R} \$ \\
17.131,55 \\
\end{array}$ & $\begin{array}{l}\mathrm{R} \$ \\
26.768,04\end{array}$ \\
\hline 6,5 bar & $\mathrm{R} \$ 1.227,21$ & $\mathrm{R} \$ 4.908,82$ & $\begin{array}{l}\mathrm{R} \$ \\
11.044,86 \\
\end{array}$ & $\begin{array}{l}\mathrm{R} \$ \\
19.635,30 \\
\end{array}$ & $\begin{array}{l}\mathrm{R} \$ \\
30.680,16 \\
\end{array}$ \\
\hline 7,0 bar & $\mathrm{R} \$ 1.390,16$ & $\mathrm{R} \$ 5.560,64$ & $\begin{array}{l}\mathrm{R} \$ \\
12.511,45 \\
\end{array}$ & $\begin{array}{l}\text { RS } \\
22.242,57\end{array}$ & $\begin{array}{l}\mathrm{R} \$ \\
34.754,02\end{array}$ \\
\hline 7,5 bar & $\mathrm{R} \$ 1.559,25$ & $\mathrm{R} \$ 6.237,00$ & $\begin{array}{l}\mathrm{R} \$ \\
14.033,26\end{array}$ & $\begin{array}{l}\mathrm{R} \$ \\
24.948,02\end{array}$ & $\begin{array}{l}\mathrm{R} \$ \\
38.981,28\end{array}$ \\
\hline 8,0 bar & $\mathrm{R} \$ 1.734,18$ & $\mathrm{R} \$ 6.936,73$ & $\begin{array}{l}\mathrm{R} \$ \\
15.607,64 \\
\end{array}$ & $\begin{array}{l}\mathrm{R} \$ \\
27.746,91\end{array}$ & $\begin{array}{l}\mathrm{R} \$ \\
43.354,54\end{array}$ \\
\hline 8,5 bar & $\mathrm{R} \$ 1.914,69$ & $\mathrm{R} \$ 7.658,75$ & $\begin{array}{l}\mathrm{R} \$ \\
17.232,20 \\
\end{array}$ & $\begin{array}{l}\mathrm{R} \$ \\
30.635,03\end{array}$ & $\begin{array}{l}\mathrm{R} \$ \\
47.867,23\end{array}$ \\
\hline 9,0 bar & $\mathrm{R} \$ 2.100,54$ & $\mathrm{R} \$ 8.402,15$ & $\begin{array}{l}\mathrm{R} \$ \\
18.904,84\end{array}$ & $\begin{array}{l}\mathrm{R} \$ \\
33.608,60\end{array}$ & $\begin{array}{l}\mathrm{R} \$ \\
52.523,43\end{array}$ \\
\hline
\end{tabular}

Fonte: Autoria própria (2019). 
Percebe-se pelos resultados, que os custos com vazamentos são muito elevados, gerando um enorme prejuízo ao longo do ano, principalmente quando os vazamentos são acúmulos de pequenos diâmetros, que muitas vezes passam despercebidos. Peças desgastadas como conexões e mangueiras ressecadas são os maiores causadores de vazamentos, por isso é importante instalar peças de qualidade, com boa durabilidade. Sendo assim, as rotinas de manutenção devem ficar atentas aos ruídos de vazamentos e assim que identificados, consertá-los.

\section{ECONOMIA RELACIONADA À TEMPERATURA DE ADMISSÃO DO AR}

Os resultados derivados do Quadro 02 são bastante promissores, chegando a reduções de energia significativas. Usar o ar exterior com uma temperatura menor para admissão é uma técnica simples de realizar, que não envolve custos elevados, somente algumas seções de tubos, e pode-se chegar a economias de mais de $5 \%$ sobre a fatura de energia elétrica.

Para a visualização dos resultados, as características do Quadro 02 foram atribuídas ao sistema de ar comprimido, exprimindo assim o fator de redução da potência com a redução da temperatura de admissão do ar:

Figura 04: Percentual de redução de potência com a redução da temperatura de admissão.

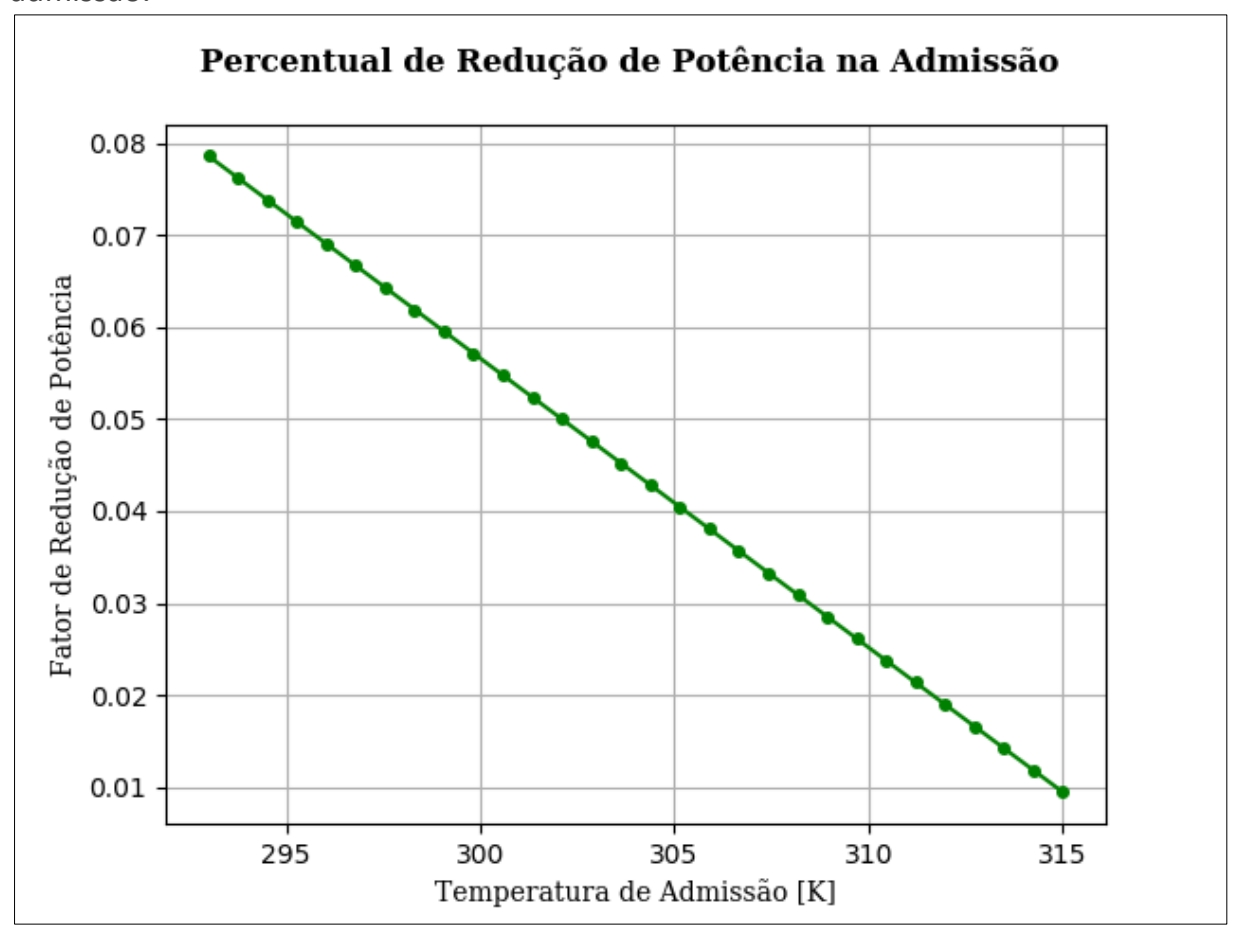

Fonte: Autoria própria (2019).

Pode-se perceber um comportamento linear do fator de redução de potência com a temperatura de admissão do ar. Nota-se que em média a cada 3 unidades de temperatura reduzidas gera-se uma economia de $1 \%$, e reduzindo a temperatura de $45^{\circ} \mathrm{C}$ para $20^{\circ} \mathrm{C}$, que é uma tarefa nada complexa, chega-se a uma redução de $8 \%$ sobre a potência consumida pelo compressor. 
Os procedimentos descritos pelo Quadro 03 são os mais eficientes quando se trata de economia de energia. A redução da pressão máxima de trabalho gera ótimos resultados, pois quanto maior for a pressão entregue pelo compressor à linha, maior será o trabalho realizado por ele.

Por isso é importante se trabalhe com a pressão mínima exigida pela planta industrial, utilizando de pulmões e reservatórios em equipamentos que tenham picos elevados de consumo de ar durante o horário de trabalho. Medidas como essa geram economias de dinheiro ao longo do ano, muitas vezes ultrapassando facilmente o valor investido em reservatórios de ar para equilibrar e manter a pressão da rede.

A Figura 05 abaixo, mostra os resultados obtidos com a redução de pressão máxima de 7,5 bar para diversos valores abaixo dele, até a pressão de 5,0 bar. Os dados característicos do sistema de compressão encontram-se abaixo:

- Consumo de energia anual: $\mathrm{R} \$ 50.000,00$;

- Pressão máxima de trabalho atual: 7,5 bar;

- Pressão atmosférica (a nível do mar): 1,01 bar;

- Razão entre os calores específicos do ar: 1,4;

Figura 05: Relação da economia anual obtida com a redução da pressão máxima da linha.

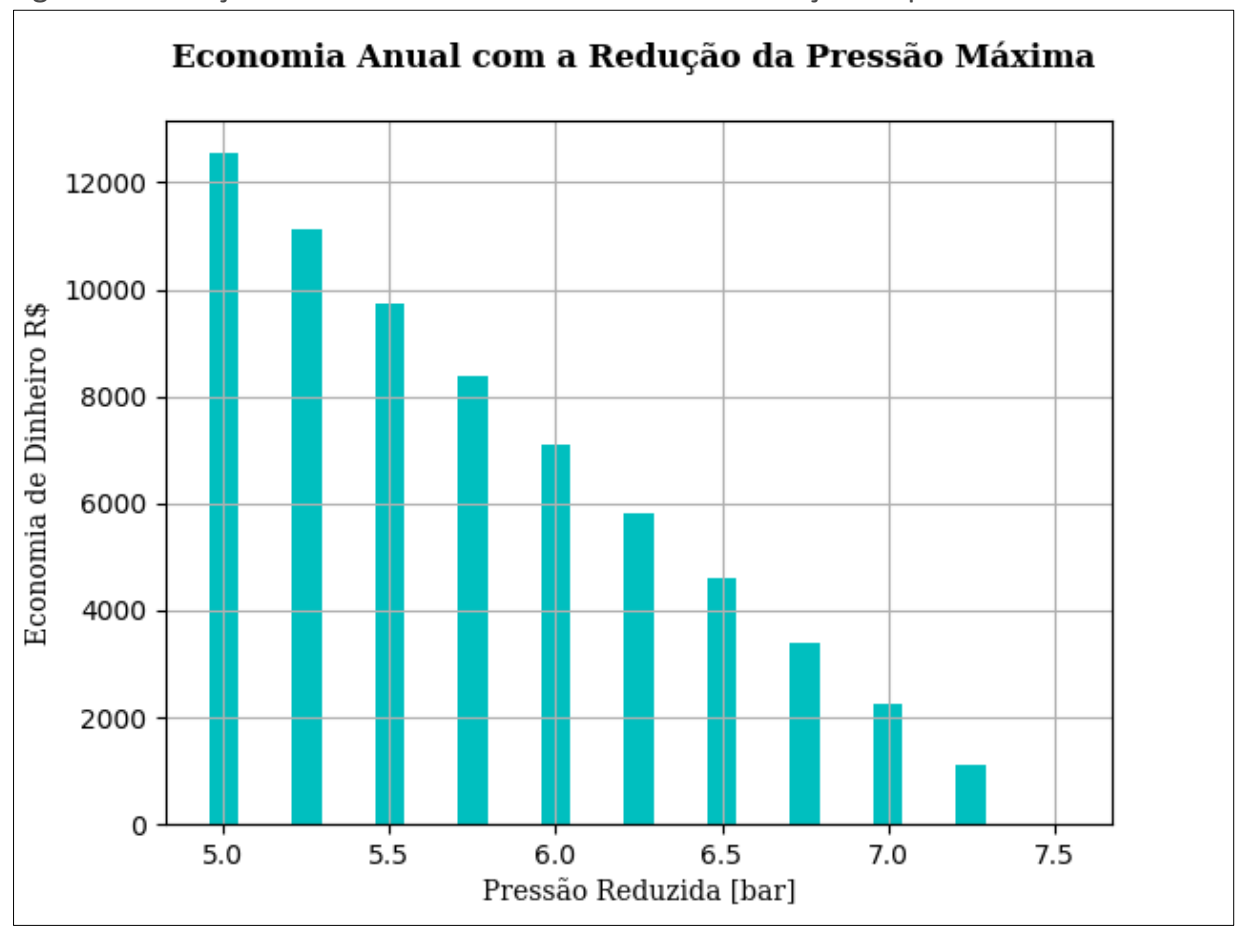

Fonte: Autoria própria (2019).

O gráfico acima demonstra a grande economia obtida com uma simples redução da pressão máxima de trabalho do sistema de ar comprimido. Para uma fatura de 50 mil reais por ano de energia elétrica associada ao sistema de ar comprimido, uma redução da pressão máxima de 7,5 bar para 6,0 bar resulta em uma economia de pouco mais de 7 mil reais durante o ano, sendo que uma redução nestas proporções se torna trivial, eliminando todos os vazamentos possíveis que resultem numa queda de pressão, e instalando reservatórios de ar em máquinas que tenham altos picos de vazão. 
Os filtros de mangas são equipamentos muitas vezes esquecidos por boa parte da gestão das empresas, pois dificilmente ocorrem problemas com eles, e, além disso, ficam no exterior das plantas industriais, porém, o filtro de mangas é um dos equipamentos que mais consomem ar comprimido nas empresas, sendo responsáveis por uma grande fatia da fatura de energia elétrica provinda da compressão do ar.

Para obter os resultados mostrados abaixo foi simulado o consumo de ar em um filtro de mangas do tipo pulse-jet, demonstrando assim uma relação entre o custo em reais pelos tempos de limpeza, tanto o tempo do jato para a limpeza, quanto o tempo de intervalo de limpeza entre uma fileira e outra. As características do filtro são dadas como:

- Quantidade de mangas: 144;

- Quantidade de fileiras: 12 ;

- Mangas em cada fileira: 12

- Pressão da linha de ar comprimido: 6,5 bar;

- Temperatura de admissão do ar: $25^{\circ} \mathrm{C}$;

- Temperatura de ar na linha: $26^{\circ} \mathrm{C}$;

- Eficiência do motor do compressor: 0,99;

- Eficiência do compressor: 0,80;

- Regime de trabalho do filtro: 2800 horas/ano;

- Custo unitário de energia: $\mathrm{R} \$ 0,355 / \mathrm{kWh}$;

Em filtros de mangas deste porte é comum utilizar válvula de alta vazão de tamanho $3 / 4 \mathrm{NPT}$, a qual possui um diâmetro interno de aproximadamente $21 \mathrm{~mm}$, conforme tubulação padrão DIN 2440, sendo este diâmetro utilizado para as simulações de vazão e consumo, obtendo assim o custo anual relacionado ao consumo de ar comprimido para a limpeza das mangas, considerando as características acima, conforme ilustra a Figura 06 abaixo.

Figura 06: Custos associados ao tempo de limpeza das mangas de filtros pulse-jet.

Custos Anuais de Compressão de Ar para Limpeza de Mangas

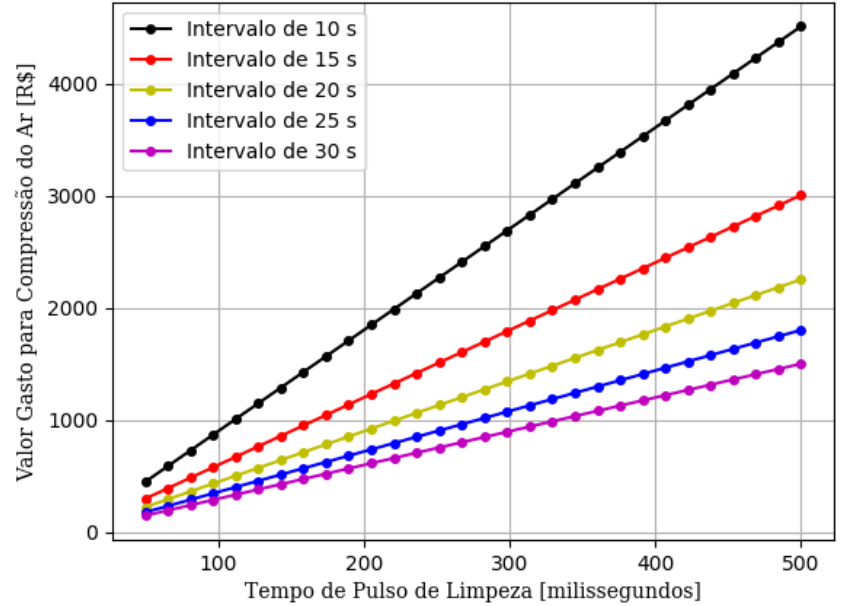

Fonte: Autoria própria (2019). 
Nota-se uma grande economia no gráfico acima, ilustrado na Figura 06, quando se aumenta o intervalo de limpeza em apenas 5 segundos, gerando uma economia em torno de $\mathrm{R} \$ 1.500,00$ por ano. E quando se trabalha na diminuição do intervalo e também do tempo de pulso a redução de custo é ainda maior.

Os resultados são satisfatórios levando em conta que empresas do setor moveleiro e madeireiro possuem, muitas vezes, várias unidades de filtros de mangas desta natureza, e uma pequena redução e/ou manejo dos tempos em cada equipamento acaba gerando uma economia imensa. Desta forma, é importante que os gestores tenham uma atenção redobrada a estes equipamentos, que possuem alto consumo de ar comprimido e consequentemente alto custo na fatura de energia elétrica.

\section{CONSIDERAÇÕES FINAIS}

O consumo excessivo de ar comprimido tem sido fatores de preocupação aos gestores industriais, devido ao alto custo de processamento e operação, para isso, novas tecnologias, motores mais eficientes, compressores mais modernos tem sido alvo das plantas industriais. Porém de nada adianta ter os mais eficientes sistemas de compressão de ar se o processo e operação envolvem muitos desperdícios, para tanto é necessário que haja um engajamento entre as equipes de manutenção e produção para sanar problemas muitas vezes simples, como um vazamento, mas que resulta em uma enorme economia ao longo do ano, conforme mostraram os resultados.

Em geral, resultados atrativos são obtidos com procedimentos simples mostrados ao longo do presente estudo, sendo propostas realistas e de fácil execução, como por exemplo: reparação dos vazamentos de ar, redução da pressão máxima de trabalho do compressor, redução da temperatura de admissão do ar, e manejo dos tempos de limpeza das mangas dos filtros do tipo pulse-jet.

Vale ressaltar que, conforme mostrado, os vazamentos de ar são os maiores responsáveis da perda de energia associada ao sistema de ar comprimido, visto que o ar vazado terá que ser novamente comprimido e novamente o compressor terá que realizar trabalho, e assim, gerando custos na fatura de energia. É importante que os reparos de ar comprimido sejam efetuados assim que detectados, ou aos finais de semana quando a planta estiver sem produção, pois sem o ruído das máquinas a detecção do vazamento se torna mais eficiente. 


\title{
Reduction of costs in the generation of compressed air in industrial installations
}

\begin{abstract}
Compressed air is as useful as electricity in many applications within industrial plants, with few production processes that do not utilize this powerful fluid. The breadth of the use of compressed air systems brings with it a series of energy waste, accompanied by the lack of awareness of the numerous opportunities of efficiency improvements of the installations responsible for air compression. A large proportion of the industry's electricity invoice corresponds to the generation of compressed air, which, if wasted, translates into money thrown away. The purpose of this paper is to demonstrate simple procedures for a better efficiency in the production and use of compressed air, thus quantifying the money savings associated with each technique. Among the topics covered are: air leaks, air inlet temperature by the compressor, maximum line working pressure, and air consumption in pulse-jet type air filters. The results of each procedure prove that simple techniques of negligible cost, and even greater control and monitoring of the consumption and production of compressed air, bring satisfactory economic returns.
\end{abstract}

KEYWORDS: Compressed Air. Efficiency. Economy. 


\section{REFERÊNCIAS}

AMERICAN CONFERENCE OF GOVERNMENTAL INDUSTRIAL HYGIENISTS - ACGIH. Industrial Ventilation: A Manual of Recommended Practice. 23 Ed. USA, 1998.

ASCOVAL INDÚSTRIA E COMÉRCIO LTDA. Válvulas de Pulso para Coletores de Pó Tipo Filtros de Manga. São Paulo, 2010.

BEJAN, A. Advanced Engineering Thermodynamics. 2o Ed. Nova York: Wiley Interscience, 1977.

BORGNAKKE, C.; SONNTAG, R. E. Fundamentos da Termodinâmica. São Paulo: Blücher, 730 p., 2013.

ÇENGEL, Y. A.; CERCI, Y. 2000. Opportunities to Save Energy in Industry. Turkish National Conference on Thermal Sciences and Technologies with International Participation, Conference Proceeding, Vol. 2. Sakarya/Turkey, 2: 392-399.

ÇENGEL, Y. A.; BOLES, M. A. Termodinâmica. $5^{\circ}$ Ed. São Paulo: McGraw-Hill, 740 p., 2006.

DINDORF, R. Estimate Opportunities of Energy Savings in Compressed air Systems. (in Polish). Energetyka, № 1, 2010.

EDWARDS, P. Compressed Air Systeims Energy Reduction Basics. Ingersoll-Rand Coinpany, Davidson, NC (EUA), 1998.

FELLER, W. F. E. Air Compressors: Their Installation, Operation, and Maintenance. Nova York: McGraw-Hill, 1944.

FONSECA, J. J. S. Metodologia da pesquisa científica. Fortaleza: UEC, 2002. Apostila.

FOX, R. W.; MCDONALD, A. T.; PRITCHARD, P. J. Introdução à Mecânica dos Fluidos. 70 Ed. Rio de Janeiro: LTC, 2010.

GIL, A. C. Como elaborar projetos de pesquisa. 4o Ed. São Paulo: Atlas, 2007.

HORTA, F. J. N. Eficiência Energética em Sistemas de Ar Comprimido. Eletrobrás/Procel, 2004. 
MACINTYRE, A. J. Ventilação Industrial e Controle da Poluição. 2o Ed. Rio de Janeiro: LTC, 1990.

MORAN, M. J.; SHAPIRO, H. N. Princípios de Termodinâmica para Engenharia. 7o Ed. Rio de Janeiro: LTC. 840 p., 2013.

RISI, J. D. Energy Savings With Compressed Air. Energy Engineering, 1995. 92(6):49-58.

ROCHA, C. R.; MONTEIRO, M. A. G. Eficiência Energética em Sistemas de Ar Comprimido: Manual Prático. Rio de Janeiro: Eletrobrás, 2005.

SEABRA, G. F. Pesquisa Científica: o Método em Questão. Brasília: Editora da UnB, 2001.

TALBOTT, E. M. Compressed Air Systems: A Guidebook on Energy and Cost Savings. 2으. Ed. The Fairmont Press, Inc.: Liburn, GA 00247, 1993.

Recebido: 06 Fev. 2019

Aprovado: 11 Out. 2020

DOI: 10.3895/gi.v16n3.9543

Como citar:

VIDAL, J. et al. Redução dos custos na geração de ar comprimido em instalações industriais. R. Gest. Industr., Ponta Grossa, v. 16, n. 3, p. 175-193, Jul./Set. 2020. Disponível em:

https://periodicos.utfpr.edu.br/revistagi

Correspondência:

Jaisson Vidal

Estrada Rio Negro, número 203, apartamento 01, Bairro Rio Negro, São Bento do Sul, Santa Catarina, Brasil.

Direito autoral: Este artigo está licenciado sob os termos da Licença Creative Commons-Atribuição 4.0

Internacional.

\section{(c) (1)}

